\title{
Does off-pump total arterial grafting increase the incidence of intraoperative graft failure?
}

\author{
Lognathen Balacumaraswami, FRCS ${ }^{\mathrm{a}}$ \\ Yasir Abu-Omar, MRCS ${ }^{a}$ \\ Kyriakos Anastasiadis, MD ${ }^{a}$ \\ Bikram Choudhary, MBBS ${ }^{a}$ \\ David Pigott, FRCA ${ }^{\mathrm{b}}$ \\ Siu-Kae Yeong ${ }^{\mathrm{c}}$ \\ David P. Taggart, MD, PhD, FRCS ${ }^{a}$
}

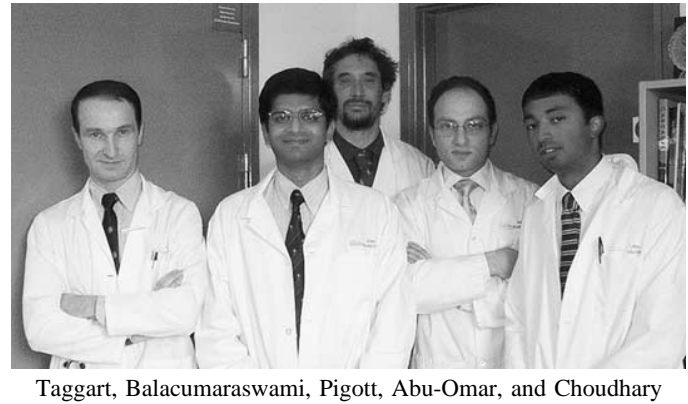

(left to right)
Background: Early graft failure is a common cause of cardiac mortality and morbidity after coronary artery bypass grafting, but there is little information on its natural incidence. Furthermore, there is particular concern about graft patency in off-pump coronary artery bypass grafting and total arterial grafting.

Methods: We performed a prospective observational study to assess intraoperative graft patency in patients undergoing off-pump and onpump coronary artery bypass grafting, who also underwent total arterial grafting. We used an intraoperative imaging system, SPY (Novadaq Technologies Inc), based on the fluorescent properties of indocyanine green dye.
From the Departments of Cardiothoracic Surgery $^{\mathrm{a}}$ and Anaesthesia, ${ }^{\mathrm{b}}$ John Radcliffe Hospital, Oxford, United Kingdom, and the National Research Council of Canada, ${ }^{\mathrm{c}}$ Ottawa, Ontario, Canada.

Lognathen Balacumaraswami (the first author) was partly funded by the Oxford University Medical Research Fund.

Received for publication Sept 19, 2003; revisions requested Nov 18, 2003; accepted for publication Nov 20, 2003.

Address for reprints: David P. Taggart, MD, Department of Cardiothoracic Surgery, John Radcliffe Hospital, Headley Way, Headington, Oxford OX3 9DU, United Kingdom (E-mail: david.taggart@ orh.nhs.uk).

J Thorac Cardiovasc Surg 2004;128:238-44 $0022-5223 / \$ 30.00$

Copyright () 2003 by The American Association for Thoracic Surgery

doi:10.1016/j.jtcvs.2003.11.072
Results: We assessed the intraoperative graft patency of 533 conduits in 200 patients. The mean number of grafts was 2.7 per patient. Of these patients, 155 (78\%) had off-pump coronary artery bypass grafting, and 45 (22\%) had on-pump coronary artery bypass grafting. Overall, $161(80 \%)$ had total arterial grafting, with composite arterial grafting performed in $120(60 \%)$ patients. Fluorescence, confirming graft patency, was observed in all but $8(1.5 \%)$ conduits in $8(4 \%)$ patients, necessitating graft revision. Six (3.9\%) and 2 (4.4\%) of these patients, respectively, had off-pump coronary artery bypass grafting and on-pump coronary artery bypass grafting.

Conclusion: Intraoperative fluorescence imaging demonstrated a low (1.5\%) but well-defined incidence of intraoperative graft failure, which affects around $4 \%$ of patients. This emphasizes the need for routine assessment of graft patency. Intraoperative fluorescence imaging permits detection and revision of failed grafts in the operating room. We found no difference in the incidence of failed grafts when comparing on-pump and off-pump total arterial grafting.

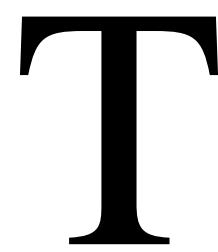

here is growing evidence that arterial grafts ${ }^{1-3}$ and off-pump coronary artery bypass grafting (OPCABG $)^{4}$ improve the outcome of coronary revascularization.

However, total arterial grafting (TAG) and OPCABG are considered to be technically more demanding, and there are continuing concerns that OPCABG results in both a reduced number of grafts 5 and inferior patency rates. ${ }^{6-8}$ Cheng and colleagues ${ }^{5}$ reported that technical difficulties in constructing anastomoses resulted in incomplete revascularization in patients undergoing OPCABG (mean distal anastomoses, 1.9 vs $3.3 ; P<.001$ ) when compared with those undergoing on-pump coronary artery bypass grafting 
(ONCABG) ${ }^{5}$ Sabik and colleagues ${ }^{9}$ likewise reported a significantly lower number of grafts in patients undergoing OPCABG (2.8 vs $3.5, P<.001)$, particularly to the circumflex and right coronary territories. Gundry and associates $^{7}$ reported that $20 \%$ of patients undergoing OPCABG required either a coronary angioplasty or redo coronary artery bypass grafting (CABG) for recurrent symptoms. Most recently, in a prospective randomized trial of 104 patients allocated to ONCABG or OPCABG, Khan and colleagues $^{8}$ reported an inferior 3-month angiographic patency rate of $88 \%$ in the OPCABG group compared with $98 \%$ in the ONCABG group $(P<.01)$.

Recently, we described the value of an intraoperative fluorescence imaging (IFI) system (SPY, Novadaq Technologies Inc) to confirm graft patency. ${ }^{10}$ We have now used this system to prospectively compare graft patency in patients undergoing, predominantly, total arterial grafts in the setting of ONCABG and OPCABG.

\section{Material and Methods}

All patients undergoing CABG performed by a single surgeon (DPT) between November 2001 and June 2003 were included in the study, with the exception of a few cases when the imaging system was not available. Our general principle is to perform off-pump TAG whenever practical and feasible. In general, ONCABG is performed in patients with poor left ventricular function (ejection fraction, $<25 \%$ ). Likewise, there is a higher use of vein grafts rather than radial artery grafts in patients with poor left ventricular function because of the higher likelihood of need for inotropic support.

Intraoperative graft patency data were collected prospectively in patients undergoing CABG with the IFI system (SPY, Novadaq Technologies Inc) on the basis of fluorescence of indocyanine green (ICG). We have described this technique previously. ${ }^{10}$ Briefly, ICG rapidly binds to plasma proteins when injected intravenously and fluoresces (emits light at $830 \mathrm{~nm}$ ) when illuminated with a monochromatic laser light source at $806 \mathrm{~nm}$. The fluorescence is captured on a charged couple device video camera. The low-intensity laser, with a total output of $2.7 \mathrm{~W}$ over an area of 7.5 $\times 7.5 \mathrm{~cm}$ at a distance of $30 \mathrm{~cm}$ above the heart, has an excellent safety profile for both the patient and theater staff. In particular, it does not require any eye protection. The system has CE marking in Europe, which allows patient use in the European community.

ICG has been widely used in clinical practice, particularly in ophthalmic angiography, for over 4 decades and has an excellent safety profile. The incidence of allergic reaction to ICG is approximately 1:40,000 and has been reported especially in patients allergic to iodine. ${ }^{11}$ The risk is strongly dose dependent, being greatest with doses greater than $0.5 \mathrm{mg} / \mathrm{kg}$ body weight.

The sterile draped camera head, guided by a range detector diode, was positioned at $30 \mathrm{~cm}$ above the heart. After completion of the distal coronary anastomosis, $1 \mathrm{~mL}(0.03 \mathrm{mg} / \mathrm{kg}$ weight $)$ of ICG dye was injected into the oxygenator in the ONCABG group or through the central venous line and flushed through with $10 \mathrm{~mL}$ of normal saline in the OPCABG group. Screening was started at the time of injection, and the grafts were imaged as the fluorescent dye passed through them. Images were then recorded on the computer hard drive. The procedure took approximately 3 minutes per anastomosis. Skeletonized conduits provided better visualization than pedicled ones. The appearance of fluorescent images as the dye passed through the bypass grafts confirmed graft patency.

\section{Surgical Technique}

All patients underwent CABG through a median sternotomy. Both internal thoracic arteries (ITAs) were harvested as skeletonized conduits. The radial artery (RA) was harvested and stored in heparinized blood containing phenoxybenzamine in the earlier patients ${ }^{12}$ and additional verapamil in the later patients ${ }^{13}$ before performing the anastomosis. The long saphenous vein was harvested by using a minimally invasive technique.

Although there are several variations depending on precise coronary anatomy and disease patterns, our basic primary strategy for construction of anastomoses was to place the right ITA (RITA) to the left anterior descending artery, the left ITA (LITA) to the obtuse marginal branch of the circumflex artery, and a composite RA graft from the LITA to the posterior descending branch of the right coronary artery.

The ITA conduits were used as in situ grafts to perform single or sequential distal coronary anastomoses. Some of the ITA and RA conduits were recycled and used for constructing composite $Y$ grafts to maximize their use. In a few cases, the recycled free ITA conduits were anastomosed as Y grafts from the parent in situ ITA to achieve composite grafting. Where possible, composite multivessel grafting was performed to achieve TAG, with complete avoidance of aortic manipulation.

\section{ONCABG}

Cardiopulmonary bypass (CPB) was instituted by using ascending aortic cannulation and a 2-stage venous cannulation in the right atrium. A standard CPB circuit incorporated a roller pump (Jostra HL 20) and a hollow-fiber membrane oxygenator (Affinity NT, Medtronic). The extracorporeal circuit was primed with $1000 \mathrm{~mL}$ of Hartmann solution and 2500 IU of heparin. Nonpulsatile flow with a flow rate of $2.4 \mathrm{~L} \cdot \mathrm{m}^{-2} \cdot \mathrm{min}^{-1}$ was maintained. Arterial filtration was not used. Cardiotomy suction was used. Acid-base balance was managed with alpha-stat control. The temperature was allowed to drift to $34^{\circ} \mathrm{C}$ during construction of anastomoses before rewarming. Myocardial protection was achieved with intermittent antegrade cold crystalloid cardioplegia. On completion of all distal anastomoses, the aortic crossclamp was removed, and the proximal anastomosis was performed with partial clamping.

\section{OPCABG}

Complete anticoagulation with heparin was achieved as in the CPB group. The lateral and inferior walls were exposed by means of a combination of a deep pericardial stay suture, Trendelenberg and right decubitus positions, and opening of the right side of the pericardium to the inferior vena cava. Regional myocardial immobilization was achieved with a suction stabilizer (Octopus, Medtronic Inc; Guidant, Cardiothoracic Systems Inc). The target coronary vessels were snared proximally with a silastic sling. In our earlier experience, an intracoronary shunt (Guidant Axius) was used when there were signs of electrocardiographic instability or excessive bleeding during construction of the anastomosis. Lat- 


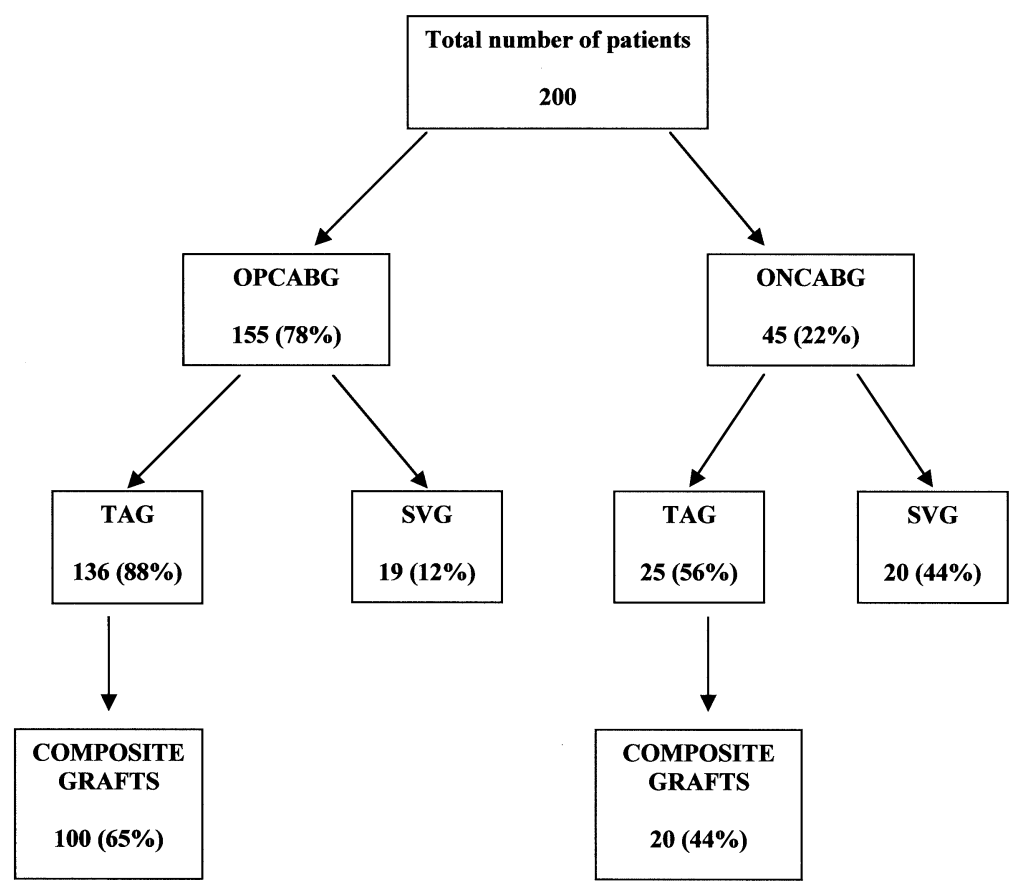

Figure 1. Flow diagram. $O P C A B G$, Off-pump coronary artery bypass grafting; $O N C A B G$, on-pump coronary artery bypass grafting; $T A G$, total arterial graft; $S V G$, saphenous vein graft.

terly shunts have been used routinely. A surgical blower-mister device enhanced visualization (Medtronic Clearview, Medtronic Inc).

Off-pump TAG with avoidance of aortic manipulation was achieved in $84.5 \%$ of cases. In the occasional cases in which saphenous vein grafts were performed, proximal anastomoses were made to the ascending aorta at a controlled systolic pressure of between 70 and $80 \mathrm{~mm} \mathrm{Hg}$ and a side-biting vascular clamp.

\section{Statistical Analysis}

Results for categoric variables are expressed as numbers (percentages of total). Continuous variables are presented as means \pm SD. The $\chi^{2}$ test was used for comparison of categoric variables. The continuous variables were compared by using the Student $t$ test.

\section{Results}

Intraoperative graft patency was assessed in 200 patients. Our previously reported preliminary experience of 84 patients is included in this study. ${ }^{10} \mathrm{~A}$ total of 533 distal coronary anastomoses were constructed. The ONCABG group includes 3 patients with concomitant aortic valve replacement and 1 patient undergoing reoperative CABG. In the OPCABG group 5 patients underwent reoperative CABG.

The mean number of distal anastomoses was 2.7 per patient. Of these patients, 155 (78\%) underwent OPCABG, and $45(22 \%)$ underwent ONCABG (Figure 1). The mean number of distal anastomoses for the ONCABG group was 2.9 per patient compared with 2.6 per patient for the OP-
CABG group $(P<.05$, Table 1$)$. However, the OPCABG group had a higher proportion of patients with single-vessel or double-vessel disease. In patients with triple-vessel disease, the mean number of grafts for the OPCABG and ONCABG groups was similar (OPCABG, $3.2 \pm 0.4$; ONCABG, $3.3 \pm 0.5$ ), with no difference between the 2 groups.

Overall, 161 (80\%) patients had TAG, of which composite arterial grafting was performed in $120(60 \%)$ patients. TAG was performed in $136(88 \%)$ patients in the OPCABG group and $25(56 \%)$ patients in the ONCABG group. A total of $100(65 \%)$ composite grafts were performed in patients undergoing OPCABG, which was significantly more $(P=$ $.05)$ than the $20(44 \%)$ grafts in the ONCABG group (Table 1). Excluding those with single-vessel disease, bilateral ITA conduits were used in $109(59 \%)$ patients: $87(62 \%)$ in the OPCABG group and $22(51 \%)$ in the ONCABG group.

There was no significant difference in the number and location of coronary arteries bypassed or the number of ITA grafts between the 2 groups. There were significantly more saphenous vein grafts (OPCABG, $6 \%$ of grafts; ONCABG, $24 \%$ of grafts; $P<.01)$ and significantly fewer RA grafts (OPCABG, 29\% of grafts; ONCABG, $18 \%$ of grafts; $P<$ $.05)$ used in constructing the distal anastomoses in the ONCABG group because of a higher proportion of patients with poor left ventricular function in the ONCABG group. The overall pattern of conduit use include the LITA in 216 (40.5\%) distal anastomoses, the RITA in 119 (23\%) distal 
TABLE 1. Mean age and anastomoses, diseased vessels, conduits used, and composite grafts in patients

\begin{tabular}{|c|c|c|c|}
\hline Variable & $\begin{array}{c}\text { OPCABG } \\
(n=155)\end{array}$ & $\begin{array}{l}\text { ONCABG } \\
(n=45)\end{array}$ & $P$ value \\
\hline Mean age (y) & $63.7 \pm 10.6$ & $63.2 \pm 10.7$ & .71 \\
\hline Mean anastomoses & $2.6 \pm 0.8$ & $2.9 \pm 0.9$ & .02 \\
\hline Mean anastomoses in triple-vessel disease & $3.2 \pm 0.4$ & $3.3 \pm 0.5$ & .1 \\
\hline Single-vessel disease $(\%)$ & $15(9.7)$ & $2(4.4)$ & .26 \\
\hline Double-vessel disease (\%) & $49(31.6)$ & $11(24.4)$ & .35 \\
\hline Triple-vessel disease (\%) & $91(58.7)$ & $32(71.1)$ & .13 \\
\hline BITA $(\%)$ & $87(56)$ & $22(48.9)$ & .39 \\
\hline LITA $(\%)$ & $150(97)$ & $44(98)$ & .73 \\
\hline RITA (\%) & $91(59)$ & $25(56)$ & .71 \\
\hline $\mathrm{RA}(\%)$ & $103(66)$ & $23(51)$ & .06 \\
\hline SVG $(\%)$ & $19(12)$ & $18(40)$ & $<.01$ \\
\hline Composite grafts $(\%)$ & $100(65)$ & $20(44)$ & .05 \\
\hline
\end{tabular}

OPCABG, Off-pump coronary artery bypass grafting; ONCABG, on-pump coronary artery bypass grafting; BITA, bilateral internal thoracic arteries; LITA, left internal thoracic artery; RITA, right internal thoracic artery; $R A$, radial artery; SVG, saphenous vein graft.

TABLE 2. Overall configuration of conduit use in distal anastomoses (patients, $n=200$; conduits, $n=533$ )

\begin{tabular}{|c|c|c|c|c|c|c|c|}
\hline Distal vessel & No. of patients* & $\begin{array}{l}\text { LITA, } \\
\text { n (\%) }\end{array}$ & $\begin{array}{l}\text { RITA, } \\
\text { n (\%) }\end{array}$ & $\begin{array}{c}\text { RA, } \\
\text { n (\%) }\end{array}$ & $\begin{array}{c}\text { RGEA, } \\
\text { n (\%) }\end{array}$ & $\begin{array}{c}\text { SVG, } \\
\text { n (\%) }\end{array}$ & Total \\
\hline LAD & 189 & $88(16.5)$ & $100(18.7)$ & $4(0.7)$ & - & $6(1.1)$ & 198 \\
\hline DIAG & 49 & $19(3.5)$ & $3(0.6)$ & $25(4.7)$ & - & $2(0.3)$ & 49 \\
\hline INT & 24 & $11(2)$ & $1(0.1)$ & $10(1.8)$ & - & $2(0.3)$ & 24 \\
\hline $\mathrm{OM}$ & 137 & 95 (17.7) & $8(1.5)$ & $32(6)$ & - & $15(2.8)$ & $150 \dagger$ \\
\hline $\mathrm{RCA}$ & 3 & & & $1(0.1)$ & & $2(0.3)$ & 3 \\
\hline PDA & 103 & $1(0.1)$ & $7(1.3)$ & $67(12.5)$ & $2(0.3)$ & $27(5)$ & 104 \\
\hline LVBR & 5 & $2(0.3)$ & - & $2(0.3)$ & - & $1(0.1)$ & 5 \\
\hline Total & & 216 & 119 & 141 & 2 & 55 & 533 \\
\hline
\end{tabular}

$\overline{L I T A}$, Left internal thoracic artery; $R I T A$, right internal thoracic artery; $R A$, radial artery; $R G E A$, right gastroepiploeic artery; $S V G$, saphenous vein graft; $L A D$, left anterior descending artery; DIAG, diagonal branch; INT, intermediate artery; $O M$, obtuse marginal branch of the circumflex artery; $R C A$, right coronary artery; $P D A$, posterior descending branch of the right coronary artery; $L V B R$, left ventricular branch of the right coronary artery.

*The total number of grafts to each distal coronary target might not add up due to the same vessel being grafted twice in a small number of patients. tThe total number of grafts to the obtuse marginal vessel includes 12 patients with grafts to 2 obtuse marginal vessels.

TABLE 3. Revised grafts

\begin{tabular}{|c|c|c|c|c|c|c|}
\hline No. & Age (y) & Sex & $\begin{array}{c}\text { No. of } \\
\text { diseased } \\
\text { vessels }\end{array}$ & $\begin{array}{l}\text { CABG } \\
\text { on-off } \\
\text { pump }\end{array}$ & Culprit anastomosis & Revision with good flow \\
\hline 1 & 77 & $\mathrm{M}$ & 2 & Off & LITA to LAD & Distal vein graft to $L A D$ \\
\hline 2 & 55 & $\mathrm{~F}$ & 1 & On & LITA to LAD & Revised LITA to LAD \\
\hline 3 & 66 & $\mathrm{M}$ & 3 & Off & RA from RITA as $Y$ graft to $O M$ & Revised RITA-RA anastomosis \\
\hline 4 & 57 & $\mathrm{M}$ & 3 & Off & LITA to OM & Revised LITA to OM \\
\hline 5 & 74 & $\mathrm{M}$ & 3 & On & LITA to OM & Revised LITA to OM \\
\hline 6 & 68 & $\mathrm{M}$ & 3 & Off & RA from LITA as $Y$ graft to $O M$ & Revised LITA-RA anastomosis \\
\hline 7 & 72 & $\mathrm{M}$ & 3 & Off & $\mathrm{RA}$ to diagonal branch & Revised RA to diagonal graft \\
\hline 8 & 68 & $\mathrm{~F}$ & 2 & Off & LITA to OM & Revised LITA to OM \\
\hline
\end{tabular}

$\overline{C A B G}$, Coronary artery bypass grafting; $L I T A$, left internal thoracic artery; $L A D$, left anterior descending artery; $R A$, radial artery; $O M$, obtuse marginal branch; RITA, right internal thoracic artery.

anastomoses, the RA in 141 (25.5\%) distal anastomoses, the gastroepiploic artery in $2(0.4 \%)$ distal anastomoses, and the long saphenous vein in $57(10.6 \%)$ distal anastomoses. The configuration of conduits anastomosed to various distal coronary targets is shown in Table 2. Overall, the LITA was used as a recycled conduit or in sequential grafts in 20 (10\%) patients. The RITA and RA conduits were each recycled in 3 patients. 
TABLE 4. Graft revision reports in the literature

\begin{tabular}{|c|c|c|c|c|c|c|}
\hline Published reports & Operation & $\begin{array}{l}\text { Intraoperative technology used } \\
\text { to assess graft patency }\end{array}$ & $\begin{array}{c}\text { No. of } \\
\text { patients }\end{array}$ & No. of grafts & $\begin{array}{l}\text { Graft revision } \\
\text { (\% patients) }\end{array}$ & $\begin{array}{c}\text { Graft revision } \\
\text { (\% grafts) }\end{array}$ \\
\hline$D^{\prime} A n c o n a$ and coworkers ${ }^{6}$ & OPCABG & Transit-time flowmetry & 409 & 1184 & 7.6 & 3.2 \\
\hline Falk and coworker ${ }^{17}$ & ONCABG & Thermal angiography & 370 & $\begin{array}{l}370 \\
\text { ITA, } 698 \text { SVG }\end{array}$ & - & $\begin{array}{l}5 \text { (ITA) } \\
1 \text { (SVG) }\end{array}$ \\
\hline Louagie and coworkers ${ }^{22}$ & ONCABG & Pulsed Doppler flow analysis & 352 & 909 & 2 & \\
\hline Mack and coworkers ${ }^{19}$ & MIDCABG & Conventional angiography & 103 & 103 & - & 3 \\
\hline Taggart and coworkers ${ }^{10}$ & $\begin{array}{l}\text { OPCABG and } \\
\text { ONCABG }\end{array}$ & Fluorescence imaging & 84 & 213 & 5 & 1.9 \\
\hline Walpoth and coworker 15 & ONCABG & Transit-time flowmetry & 46 & - & 6.5 & - \\
\hline Hol and coworkers ${ }^{20}$ & OPCABG & Conventional angiography & 45 & 57 & - & 5 \\
\hline Reuthebuch and coworker ${ }^{21}$ & OPCABG & $\begin{array}{l}\text { Fluorescence imaging and } \\
\text { transit-time flowmetry }\end{array}$ & 37 & 107 & - & 3.7 \\
\hline Lin and coworkers ${ }^{16}$ & MIDCABG & Pulsed Doppler flow analysis & 35 & 35 & 8.5 & 8.5 \\
\hline
\end{tabular}

OPCABG, Off-pump coronary artery bypass grafting; ONCABG, on-pump coronary artery bypass grafting; ITA, internal thoracic artery; SVG, saphenous vein graft; $M I D C A B G$, minimally invasive direct coronary artery bypass grafting.

Eight $(1.5 \%)$ grafts in $8(4 \%)$ patients demonstrated no fluorescence within the conduits during image acquisition (Table 3). None of these grafts were imaged again to demonstrate flow. Hence we cannot label any of these as spasm. None of these patients demonstrated intraoperative electrocardiographic or hemodynamic changes. In 2 patients graft failure was caused by dissection in the conduit wall, in 2 patients it was caused by intimal flaps in the native coronary vessel, in 1 patient it was caused by an inadvertent stitch in the posterior wall of the coronary vessel, and in 1 patient it was caused by kinking at the heel of the anastomoses. In 2 patients there was no readily discernable cause. Two (4.4\%) of these patients underwent ONCABG, and $6(3.9 \%)$ underwent OPCABG. There was no statistical difference in the number of grafts revised between the 2 groups. The occluded grafts were revised, after which the grafts were reimaged and patency was confirmed with the IFI system.

On initial imaging, $5(0.9 \%)$ grafts performed to the posterior descending coronary artery and $4(0.75 \%)$ to the obtuse marginal branch of the circumflex artery did not demonstrate fluorescence, whereas the heart was "distorted" by being "upended" with a suction cap. However, on subsequent imaging, with the heart in its natural position, flow could be seen in the proximal portion of the graft, confirming graft patency. We assume that lack of flow in initial imaging was due to a transient decrease in cardiac output and systemic arterial pressure combined with compression of the graft between the lateral border of the heart and the sternal edge. In one patient the RITA-to-intermediate-artery anastomosis did not demonstrate fluorescence on initial imaging in its natural position but did demonstrate satisfactory flow, with a higher systemic arterial pressure on subsequent imaging. In this case intrinsic graft spasm might be the cause.

\section{Discussion}

Although the need for coronary angiography for quality control is universally accepted for percutaneous interventions, most $\mathrm{CABG}$ operations are still performed without any immediate confirmation of a satisfactory technical result. Indeed, until recently and in the absence of suitable devices for assessment of graft patency, the current natural incidence of intraoperative graft failure has been poorly documented. Although intraoperative graft failure might be asymptomatic, it can contribute to early morbidity and mortality and adversely affect long-term outcomes. ${ }^{14}$ Consequently, there is a growing appreciation of the desirability to confirm graft patency in the operating room, particularly in the setting of new operative techniques and interventions, such as OPCABG and TAG.

Our current prospective study of 200 patients undergoing both on-pump and off-pump CABG confirms our own preliminary experience ${ }^{10}$ and the findings of others ${ }^{6}$ that there is a small but definite incidence of intraoperative graft failure that can be detected and corrected in the operating room. We found that $8(1.5 \%)$ grafts in $8(4 \%)$ patients were occluded, necessitating revision (Figures 2 and 3). It is of particular importance in these cases of graft occlusion that the surgeon was unsuspecting and that there was no hemodynamic instability or electrocardiographic evidence of myocardial ischemia in the area subtended by the grafted artery. Without formal assessment of graft patency, graft occlusion would have remained undetected.

However, in contrast to the findings of others, ${ }^{5,7-9}$ we did not find that OPCABG either reduced the number of grafts or increased the failure rate in comparison with ONCABG. Although the overall mean number of distal coronary anastomoses was significantly higher in the ONCABG group because of a higher proportion of patients with single-vessel or double-vessel disease in the OPCABG group, there was 

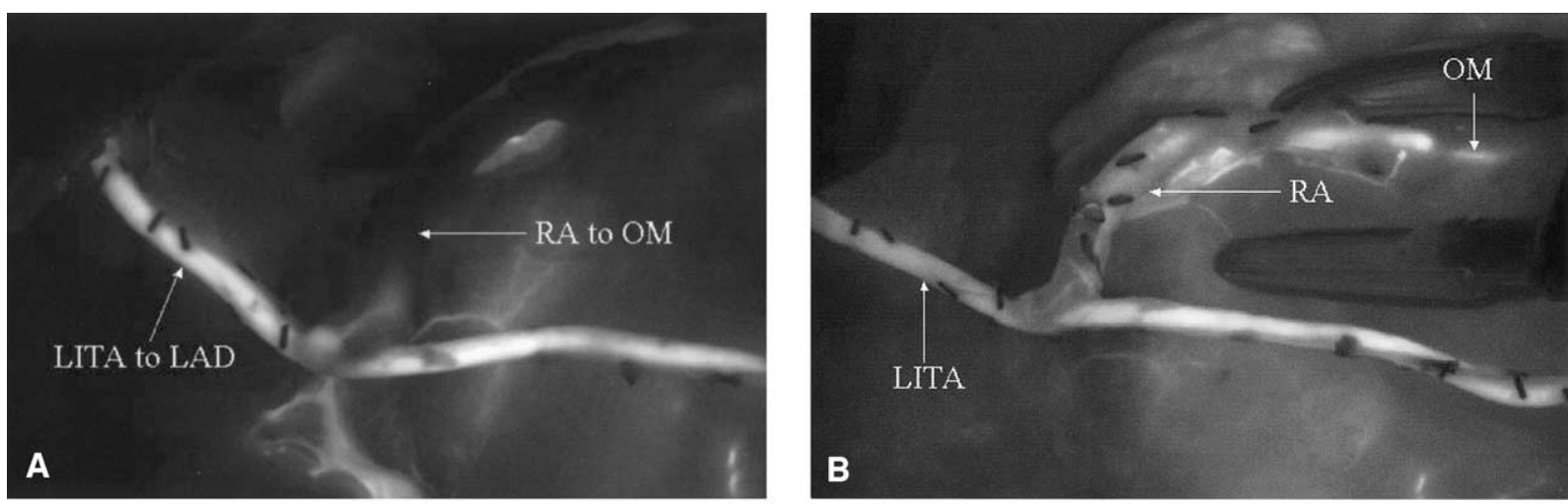

Figure 2. A, Image showing in situ left internal thoracic artery (LITA) graft to the left anterior descending (LAD) artery. A composite radial artery (RA) graft from the LITA is anastomosed to the obtuse marginal (OM) artery. Note fluorescence is not seen within the RA. B, This image was taken after revision of the LITA-to-RA anastomosis seen in panel $A$. Note that fluorescence is now seen in the RA and OM coronary artery.
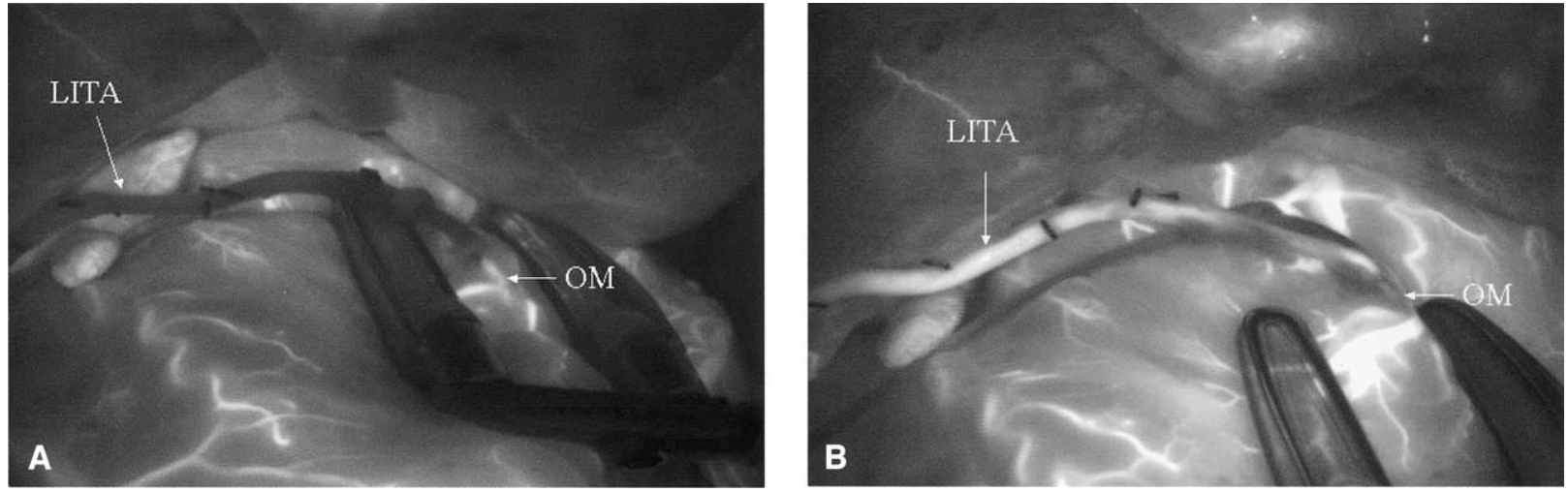

Figure 3. A, Image showing in situ anastomosis of the left internal thoracic artery (LITA) to the obtuse marginal (OM) artery. Note that no fluorescence is seen in the LITA graft but is seen in the OM artery as a result of native flow. B, Image obtained after revision of the anastomosis in panel $A$. Note that fluorescence is seen in both the LITA and the OM coronary artery.

no significant difference in the mean number of distal anastomoses in patients with triple-vessel disease in the 2 groups $(\mathrm{OPCABG}, 3.2 \pm 0.4$; ONCABG, $3.3 \pm 0.5)$

The plethora of techniques that have been proposed to confirm graft patency (Table 4) ${ }^{15-21}$ emphasizes the lack of a single and universally accepted method. Conventional coronary angiography is the gold standard technique for graft assessment but is highly invasive (requiring arterial puncture), increases operating time, and is infrequently available in the operating room. Although numerous other methods on the basis of electromagnetic, ${ }^{22}$ ultrasound, ${ }^{6,15,23}$ Doppler flow analysis, ${ }^{16}$ echocardiographic, ${ }^{24}$ and thermal angiography techniques ${ }^{25}$ have been described, all have limitations precluding their widespread use. Currently, transit-time flowmetry (TTFM) and IFI appear most promising.

TTFM uses the principle of ultrasound to measure flow in bypass grafts. A flow probe housing 2 ultrasonic trans- ducers and an acoustic reflector is used to obtain the transit time taken for the wave of ultrasound to travel from one transducer to another. The difference between the integrated transit times is a measure of the flow volume. By using TTFM, D'Ancona and colleagues ${ }^{6}$ reported the need to revise $37(3.2 \%)$ of 1145 grafts in $33(7.6 \%)$ of 409 patients undergoing OPCABG. They emphasized the reliance on correct analysis of TTFM flow patterns to correct abnormalities. Absolute mean flow values are of little value, particularly in low-flow situations, and appropriate interpretation of certain derived values, such as the pulsatility index and the diastolic flow index, are variable.

The IFI system, on the contrary, is a simple, safe, and reproducible intraoperative imaging technique that enables routine assessment of graft patency in the operating room. IFI visibly demonstrates graft patency by means of fluorescence of ICG dye as it passes through the graft. The ICG 
dye transit time is dependent on various factors, including the diameter of the conduit, systemic arterial pressure, competitive native coronary flow (depends on severity of the native stenoses), and size and state of the distal coronary vascular bed. Proximal snaring of the target coronary vessel with a Silastic sling after completion of the anastomosis ${ }^{6}$ eliminates competitive flow and results in a shorter dye transit time with superior fluorescent images.

Although several groups have reported intraoperative patency rates in $\mathrm{CABG}$, to our knowledge, this is the first reported study of intraoperative imaging for graft patency assessment in both ONCABG and OPCABG, which provides evidence to support its routine use in $\mathrm{CABG}$.

\section{Limitations}

This is an observational study with all grafts performed by a single surgeon and might overestimate or underestimate the true natural incidence of graft failure. The results are, however, consistent with the incidence of graft failure observed in other reports in the literature. Although the IFI system confirms intraoperative graft patency, it does not permit precise angiographic assessment of the quality of the anastomosis and hence cannot ensure long-term patency, which would require angiographic follow-up studies. The IFI system would be considerably enhanced by means of quantification of graft flow.

\section{Conclusion}

IFI demonstrated a low but well-defined incidence of intraoperative graft failure in both on-pump and off-pump operations, which underlines the need for routine assessment of graft patency. An IFI system allows verification of graft patency and immediate correction of failed grafts and should be considered for routine use in patients undergoing CABG.

The camera and the dye were provided by Novadaq Technologies Inc (Toronto, Canada) for investigational purposes.

\section{References}

1. Lytle B, Blackstone E, Loop F, Houghtaling P, Arnold J, Akhrass R, et al. Two internal thoracic artery grafts are better than one. $J$ Thorac Cardiovasc Surg. 1999;117:855-72.

2. Endo M, Tomizawa $Y$, Nishida $H$. Bilateral versus unilateral internal mammary revascularization in patients with diabetes. Circulation. 2003;108:1343-9.

3. Taggart DP, D'Amico R, Altman DG. Effect of arterial revascularisation on survival: a systematic review of studies comparing bilateral and single internal mammary arteries. Lancet. 2001;358:870-5.

4. Abu-Omar Y, Taggart DP. Off-pump coronary artery bypass grafting. Lancet. 2002;360:327-30.

5. Cheng W, Denton TA, Fontana GP, Raissi S, Blanche C, Kass RM, et al. Off-pump coronary surgery: effect on early mortality and stroke. J Thorac Cardiovasc Surg. 2002;124:313-20.

6. D'Ancona G, Karamanoukian HL, Ricci M, Schmid S, Bergsland J, Salerno TA. Graft revision after transit time flow measurement in off-pump coronary artery bypass grafting. Eur J Cardiothorac Surg. 2000;17:287-93
7. Gundry SR, Romano MA, Shattuck OH, Razzouk AJ, Bailey LL. Seven-year follow-up of coronary artery bypasses performed with and without cardiopulmonary bypass. J Thorac Cardiovasc Surg. 1998; 115:1273-8.

8. Khan NE, De Souza A, Mister R, Flather M, Clague J, Davies S, et al. A randomized comparison of off-pump and on-pump multivessel coronary artery bypass surgery. New Engl J Med. 2004;350:21-8.

9. Sabik J, Gillinov A, Blackstone E, Vacha C, Houghtaling P, Navia J, et al. Does off-pump coronary surgery reduce morbidity and mortality? J Thorac Cardiovasc Surg. 2002;124:698-707.

10. Taggart DP, Choudhary B, Anastasiadis K, Abu-Omar Y, Balacumaraswami L, Pigott DW. Preliminary experience with a novel intraoperative fluorescence imaging technique to evaluate the patency of bypass grafts in total arterial revascularization. Ann Thorac Surg. 2003;75:870-3.

11. Speich R, Saesseli B, Hoffmann U, Neftel KA, Reichen J. Anaphylactoid reactions after indocyanine-green administration. Ann Intern Med. 1988;109:345-6.

12. Taggart DP, Dipp M, Mussa S, Nye PC. Phenoxybenzamine prevents spasm in radial artery conduits for coronary artery bypass grafting. J Thorac Cardiovasc Surg. 2000;120:815-7.

13. Mussa S, Guzik TJ, Black E, Dipp MA, Channon KM, Taggart DP. Comparative efficacy and duration of action of phenoxybenzamine, verapamil/nitroglycerine and papaverine as topical antispasmodics for radial artery coronary artery bypass grafting. $J$ Thorac Cardiovasc Surg. 2003;126:1798-805.

14. Yusuf S, Zucker D, Peduzzi P, Fisher LD, Takaro T, Kennedy JW, et al. Effect of coronary artery bypass graft surgery on survival: overview of 10-year results from randomised trials by the Coronary Artery Bypass Graft Surgery Trialists Collaboration. Lancet. 1994;344:56370.

15. Walpoth BH, Bosshard A, Genyk I, Kipfer B, Berdat PA, Hess OM, et al. Transit-time flow measurement for detection of early graft failure during myocardial revascularization. Ann Thorac Surg. 1998;66:1097100.

16. Lin JC, Fisher DL, Szwerc MF, Magovern JA. Evaluation of graft patency during minimally invasive coronary artery bypass grafting with Doppler flow analysis. Ann Thorac Surg. 2000;70:1350-4.

17. Falk V, Walther T, Philippi A, Autschbach R, Krieger H, Dalichau H, et al. Thermal coronary angiography for intraoperative patency control of arterial and saphenous vein coronary artery bypass grafts: results in 370 patients. J Card Surg. 1995;10:147-60.

18. Louagie YA, Brockmann CE, Jamart J, Schroeder E, Buche M, Eucher PM, et al. Pulsed Doppler intraoperative flow assessment and midterm coronary graft patency. Ann Thorac Surg. 1998;66:1282-8.

19. Mack MJ, Magovern JA, Acuff TA, Landreneau RJ, Tennison DM, Tinnerman EJ, et al. Results of graft patency by immediate angiography in minimally invasive coronary artery surgery. Ann Thorac Surg. 1999;68:383-90.

20. Hol PK, Fosse E, Lundblad R, Nitter-Hauge S, Due-Tonnessen P, Vatne $\mathrm{K}$, et al. The importance of intraoperative angiographic findings for predicting long-term patency in coronary artery bypass operations. Ann Thorac Surg. 2002;73:813-8.

21. Reuthebuch O, Haussler A, Turina M. Novadaq spy trade mark immediate bypass function control in off-pump CABG. Heart Surg Forum. 2003;6(suppl 1):S19.

22. Louagie YA, Haxhe JP, Buche M, Schoevaerdts JC. Intraoperative electromagnetic flowmeter measurements in coronary artery bypass grafts. Ann Thorac Surg. 1994;57:357-64.

23. Suematsu Y, Ohtsuka T, Miyairi T, Motomura N, Takamoto S. Ultrasonic evaluation of graft anastomoses during coronary artery bypass grafting without cardiopulmonary bypass. Ann Thorac Surg. 2002;74: 273-5.

24. Haaverstad R, Vitale N, Williams RI, Fraser AG. Epicardial colourDoppler scanning of coronary artery stenoses and graft anastomoses. Scand Cardiovasc J. 2002;36:95-9.

25. Falk V, Walther T, Kitzinger H, Rauch T, Diegeler A, Autschbach R, et al. An experimental approach to quantitative thermal coronary angiography. Thorac Cardiovasc Surg. 1998;46:25-7. 